\title{
10 health stories that mattered: Dec. 1-5
}

- Victims of thalidomide will receive more support from the federal government, promised Health Minister Rona Ambrose, though no specifics were provided. Ambrose met with representatives from the Thalidomide Victims Association of Canada, which is seeking immediate financial support as well as a long-term commitment to address the health needs of aging survivors, who were born in the 1950 s and 1960s.

- Health researchers are upset about a "secretive and disrespectful" decision at the Canadian Institutes of Health Research that would force scientists to "knock on doors" for external funding before they can access public money, reports CBC News. Speaking off the record, a member of one of the institute's advisory boards told $\mathrm{CBC}$ the reason for the change is to "push scientists to commercialize," at the expense of long-term basic science.

- To reduce how much Canadians spend on prescription drugs, provinces should coordinate purchases for a large range of medications and use competitive tendering for bulk purchases, recommends Canadian Doctors for Medicare. Billions could be saved if Canadian drug prices were brought in line with international standards, states the report, and the savings could be used to provide medications to all patients at little or no out-of-pocket cost.
- As many as 990000 Canadians may have eating disorders, $80 \%$ of them girls or women, and they face numerous challenges in seeking care, states a report from the House of Commons Standing Committee on the Status of Women. These barriers include inadequately trained health care providers, a lack of programs, lengthy wait times to receive care and insufficient research to find new treatments.

- The recently announced government funding for research into the mental health of military veterans is "a very, very meagre amount of money," Dr. Ibolja Cernak, the chair in Military and Veterans' Clinical Rehabilitation at the University of Alberta, told The Globe and Mail. It will amount to about \$1.1 million a year, an insufficient amount to conduct the basic science and clinical research needed to address a large and growing problem, according to Cernak.

- H5 avian influenza has been confirmed on two poultry farms in British Columba. "The Canadian Food Inspection Agency has placed the two farms under quarantine to control disease spread and the industry sector has been notified to adopt enhanced biosecurity practices," announced the federal government.

- If provinces provided full and universal coverage of prescription drugs, patients would benefit from improved access and equity, and governments would get more value for money than the current patchwork of private and public drug insurance plans, according to the Institute for Research on Public Policy. As a single payer, a provincial government could promote the use of lower-priced generic drugs, negotiate lower prices for brand-name drugs and improve prescribing patterns, states the report.

- The federal government and partners announced \$4.5 million for three projects to address HIV/AIDS health problems affecting men. About three-quarters of Canadians with HIV are men, who tend to access health care less frequently than women, states the government.

- About 231500 adults in Ontario, $2.2 \%$ of the adult population, seriously contemplated suicide last year, according to a survey by the Centre for Addiction and Mental Health. Suicidal ideation did not differ much by gender, but younger Ontarians (18-34 y) were nearly three times more likely to consider suicide than older respondents (55 y and over).

- Only $62 \%$ of health care workers in the Vancouver Coastal Health Authority have received the influenza vaccine so far this season, despite being required by the province to either get vaccinated or wear a mask when treating patients. Last year, the vaccination rate among the same group of workers was $82 \%$. - Roger Collier, CMAJ

CMAJ 2015. DOI:10.1503/cmaj.109-4960 